\title{
Assistive Technology for Cognition and Health-related Quality of Life in Huntington's Disease
}

\author{
Marleen R. van Walsem ${ }^{\mathrm{a}, \mathrm{b}, 1, *}$, Emilie I. Howe ${ }^{\mathrm{a}, \mathrm{c}, 1}$, Jan C. Frich $^{\mathrm{d}, \mathrm{e}}$ and Nada Andelic ${ }^{\mathrm{a}, \mathrm{c}}$ \\ ${ }^{\mathrm{a} C e n t r e}$ for Habilitation and Rehabilitation Models and Services (CHARM), Institute of Health \\ and Society, University of Oslo, Blindern, Oslo, Norway \\ ${ }^{\mathrm{b}}$ Department of Neurohabilitation, Oslo University Hospital, Nydalen, Oslo, Norway \\ ${ }^{\mathrm{c}}$ Department of Physical Medicine and Rehabilitation, Oslo University Hospital, Nydalen, Oslo, Norway \\ ${ }^{\mathrm{d}}$ Institute of Health and Society, University of Oslo, Blindern, Oslo, Norway \\ ${ }^{\mathrm{e}}$ Department of Neurology, Oslo University Hospital, Nydalen, Oslo, Norway
}

\begin{abstract}
.
Background: Assistive technology for cognition (ATC) can be defined as external devices aimed at supporting cognitive function. Studies in neurological populations suggest that use of ATC is a promising strategy to ameliorate negative effects of cognitive impairment and improve Health-related Quality of Life (HRQoL). There is a lack of studies on the effects of ATC in HD.

Objective: This study aimed to describe the use of ATC in patients with HD, and to investigate the association between ATC and HRQoL.

Methods: A cross-sectional population-based study, including eighty-four patients with a clinical HD diagnosis (stages I-V). Socio-demographic and clinical data were collected, including information regarding various aspects of ATC use and an evaluation of cognitive impairment was performed. The Unified Huntington's Disease Rating Scale (UHDRS) Total Functional Capacity scale (TFC) and the EQ-5D Visual Analogue Scale were used to evaluate functional ability and HRQoL. Descriptive analyses were conducted to describe ATC use and regression analyses to investigate associations between ATC and HRQoL.
\end{abstract}

Results: Thirty-seven percent of the patients had ATC, and ATC was used most frequently in stages I-III. Information about ATC, needs evaluation and training was provided to $44 \%, 32.1 \%$ and $20.2 \%$ respectively. The regression analysis showed a significant association between TFC and HRQoL ( $\beta$ value $=-0.564, p=0.001$ ), but there was no association between ATC and HRQoL.

Conclusions: One-third of all patients used ATC, mainly those with mild to moderate cognitive impairment (stage I - III). No association between ATC and HRQoL was found. More research is needed to investigate effects of ATC in HD.

Keywords: Neurodegenerative diseases, huntington disease, self-help devices, cognition, quality of life

\footnotetext{
${ }^{1}$ Authors contributed equally.

${ }^{*}$ Correspondence to: Marleen R. van Walsem, Centre for Habilitation and Rehabilitation Models and Services (CHARM), Institute of Health and Society, University of Oslo, P.O. Box 1130 Blindern, 0318 Oslo, Norway. Tel.: +47 22859237; Fax: +47 22850570; E-mail: r.m.v.walsem@medisin.uio.no.
}

\section{INTRODUCTION}

Cognitive impairment is one of the hallmark symptoms of Huntington's disease (HD), an autosomal dominant hereditary neurodegenerative disease. 
Subtle signs of cognitive decline appear more than a decade prior to clinical diagnosis and develop progressively [1-5]. Neuro-imaging studies have revealed alterations in brain function, -structure and -connectivity in individuals with pre-manifest and manifest HD, and has found relationships between neuro-imaging measures and poorer performance on cognitive tasks $[3,4,6,7]$. While changes in cognition vary from individual to individual, cognitive impairments are usually most pronounced in the cognitive domains of psychomotor speed, executive functions and memory (specifically visuo-spatial memory), progressing until developing global cognitive impairment and dementia in advanced stages of HD $[4,8,9]$.Cognitive impairment in HD can have a detrimental effect on health-related quality of life (HRQoL) through affecting ability to work and partake in leisure activities, interpersonal relationships, and ability to maintain self-care [10-13]. Two studies on HD have identified impaired cognitive function as the strongest negative determinants of HRQoL $[12,14]$

Despite extensive efforts, no known cure exists for $\mathrm{HD}$ at present and no pharmacological interventions have been shown to improve cognitive function in HD [15]. Patients suffering from HD are dependent on the provision of individually tailored multidisciplinary comprehensive healthcare across the disease spectrum [14, 16-18]. The broad established knowledge about cognitive impairment in relation to brain function and mechanisms that has emerged during the last decades, has contributed to an increased interest in non-invasive, non -pharmacological interventions that may have a positive effect on cognitive function $[4,19]$. Studies conducted in patients with traumatic brain injury (TBI), Alzheimer's disease and elderly with cognitive deficits, have shown that assistive technology for cognition (ATC) has the potential to support and maintain cognitive function and thereby improve functional ability and HRQoL [20-25]. Assistive technology for cognition (ATC) can be defined as an item that increases, maintains or improves functional capabilities for individuals whose cognitive changes limit their effective participation in daily activities [26]. ATC are external aids that can address disabilities in memory, executive functions such as planning, organization and attention, in addition to reduced psychomotor speed [26, 27]. Wilson et al. assessed a personalized electronic paging system as a method of reducing everyday problems in individuals with cognitive impairment (memory, attention, planning, and organizational problems) following TBI, stroke and other acquired progressive and non-progressive brain injuries. They found use of the paging system to be significantly associated with greater ability to carry out daily activities, such as self-care and keeping appointments [23]. Two studies conducted in the HD population investigated the use of talking mats as a way to support communication in nine patients. Ferm et al. examined the effect of talking mats in one-toone communication in five patients and found that they were able to have more structured conversations compared to a control group with no communication aids [28]. Hallberg et al. investigated the use of talking mats in group conversations and found that patients had more effective conversations and asked more questions with the help of talking mats [29].

Despite broad knowledge regarding cognitive impairment in HD, and literature investigating ATC as a beneficial intervention to compensate negative effects of cognitive dysfunction in patients with other neurological conditions, the two previously mentioned studies are the only studies that have been conducted on ATC in HD [28, 29]. No studies systematically describing ATC have been conducted in HD. Moreover, to the authors' knowledge, ATC as a way of alleviating cognitive impairment in HD has not been proposed as a potential cognitive intervention or as a part of comprehensive multidisciplinary care in literature on cognition in HD. Thus, there is a need for studies systematically describing the use of ATC and to investigate its potential as a nonpharmacological intervention in HD, by exploring the association between ATC and HRQoL. Otherwise we may discount an important non-pharmacological intervention for patients with HD.

The aims of the present study are to:

- Describe the use of ATC across the disease stages in a Norwegian cohort of HD patients.

- Investigate the association between ATC and HRQoL.

\section{MATERIALS AND METHODS}

\section{Participants and recruitment procedure}

A total of 158 patients with a clinical diagnosis of HD residing in the South-Eastern region of Norway (population of 2.7 million), equal to a prevalence of 5.9/100.000 inhabitants, were identified. These patients were invited to participate in a survey study on healthcare needs and utilization and quality of 
life. Eighty eight patients gave their consent to participate and were included in the survey. Of those, two patients were excluded due to lack of clinical diagnosis of HD. Of the 86 patients, 2 did not return the EQ-5D-3L for Health-related Quality of Life (HRQoL) questionnaire, resulting in 84 patients included in the data-analyses (53.2\% of the total number of patients invited to study participation) (see flow chart in Fig.1 illustrating patient recruitment).

The identification of eligible patients was completed through the regional academic medical center, Oslo University Hospital, the Department of Neurohabilitation, Department of Neurology and the Department of Medical Genetics, and through the national advisory service for HD, the Centre for Rare Disorders. Furthermore, Vikersund Rehabilitation Centre, offering a rehabilitation program for HD patients, distributed invitations to additional patients. We also collaborated with the Norwegian Professional Network for Community Care in HD (Huntington fagnettverk) and the Norwegian HD lay association (Landsforeningen for Huntington sykdom), in a further attempt to reach as many patients as possible.

Approval for the study was obtained from the Regional Ethical Committee (ref. 2013/2089). All patients included in the study provided their informed consent. For patients unable to give informed consent themselves, consent was given by the primary caregiver or legal representative.

\section{Procedures for data collection}

Data was collected from January to August 2014 either as outpatient study visits (39\%) or as study

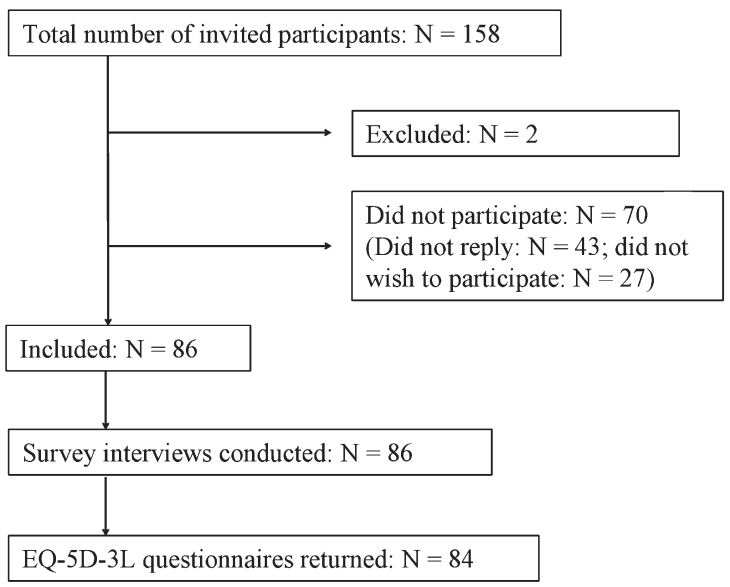

Fig. 1. Flow chart of recruitment process. visits at the patients' home $(61 \%)$. The survey interviews and patient ratings were performed by two experienced clinical psychologists (MRvW and EIH). At the beginning of the visit information on socio-demographic and clinical characteristics was collected. For three patients we were unable to obtain information about the number of CAG repeats in the HTT-gene. Furthermore, for four patients we used supplementary information from the patients' medical records in order to estimate educational level (low vs. higher) and for three patients we determined the occupational type (manual vs. non-manual). For three patients the disease duration (number of years with clinical diagnosis of HD) was estimated from information in patients' medical records. As part of the clinical characteristics a clinical evaluation of cognitive impairment was conducted. Furthermore, patients were rated regarding their functional ability and asked to report their self-experienced healthrelated quality of life (HRQoL) by filling out a generic questionnaire. Primary carers, either family members or healthcare personnel involved with the patient on a daily basis assisted patients who were unable to complete the questionnaire themselves. The primary carer completed the questionnaire on behalf of eight patients with advanced disease. They were explicitly instructed to reflect the patients experienced health status and HRQoL to the best of their ability. When unable to do so the questions were kept open and became missing values. A prepaid reply envelope was used to return questionnaires, which were not filled out during the study visit.

\section{Collecting information on assistive technologies for cognition (ATC)}

For the specific purpose of the present study, information concerning ATC was collected. The existing literature on $\operatorname{ATC}(29,31)$ suggests that individuals with cognitive impairment may start using external aids of their own in order to support impaired cognitive function, and include mainstream products such as cell phones, calendars, planner books, alarm clocks etc. We wanted to document the use of such devices and chose to define such items as informal ATC. Formal ATC was defined as items or software specifically designed to support patients with cognitive impairment acquired through a formal process of implementation. The information regarding ATC that was collected included the following: a) whether patients had ATC and whether these were formal or informal b) whether they used ATC, c) whether they 
had been informed about the possibility of receiving ATC, d) whether they had undergone a formal needs assessment for ATC, and e) whether they had received training in the use of the ATC. This information was recorded as part of the survey interview at the beginning of the study visits.

\section{Clinical evaluation of cognitive impairment}

A clinical evaluation of the patients' cognitive status was performed. This evaluation was based on information concerning cognitive function and symptoms obtained from the patient and information from their relative and/or professional caregiver, in addition to the clinicians' observations during the evaluation. The clinical evaluation of cognitive impairment included the following categories: 1) mild cognitive impairment, defined as a slight reduction in one or more cognitive domains causing changes in or impaired ability to perform daily activities and the need for minor adjustments in order to be able to perform everyday activities, with nextof-kin starting to notice changes in the patient, 2) moderate cognitive impairment, defined as overt cognitive impairment in more than one cognitive domain as compared to premorbid function, with clear need for support/adjustments in order to continue carrying out daily activities and no longer being able to perform complex tasks, evident to next of kin, 3) severe cognitive impairment, defined as severe cognitive dysfunction in all domains, impaired communication, no longer being able to carry out daily activities or maintain self-care and in need of around the clock care, 4) Unable to evaluate, defined as cases where the raters were in doubt of the patients cognitive function due to lack of comparative information from next-of-kin or primary healthcare professional.

\section{Measurements}

As a measure of functional ability, we used the Unified Huntington's Disease Rating Scale (UHDRS) - Functional Assessment, including the Total Functional Capacity scale (TFC) (scoring range of $0-$ 13), the Functional Assessment scale (FAS) rating ability to perform activities of daily living (scoring range 0-25), and the Independence Scale (IS), indicating the level of independence (scoring range 0-100). The TFC was used to classify the patients in five functional stages of HD: Stage I corresponds to a TFC score of 11-13, Stage II to a TFC score of 7-10, Stage III to a TFC score of 3-6, Stage IV to a TFC score of 1-2 and Stage V to a TFC score of 0 . Higher scores on these scales indicate better functioning.

In order to measure self-perceived overall HRQoL, we used the Visual Analogue Scale (VAS) of the EQ-5D-3L. The EQ-5D-3L is a generic measure developed by the Euro-Qol Group [30]. The VAS has a scoring range from 0 (worst health-state) to 100 (best health state) and is often used as a general measure for HRQoL. The EQ-5D-3L has been used in various health conditions including $\mathrm{HD}$, and it has been found valid to use in the Norwegian population [31-34].

\section{Statistical analysis}

Descriptive statistics of mean values and standard deviation (SD) were calculated for normally distributed variables and median and interquartile range (IQR) for non-normally distributed sociodemographic and clinical variables. Frequencies and percentages were calculated in order to describe the nominal socio-demographic and clinical variables, as well as to describe ATC use as recorded by the five information items regarding ATC. Group differences between disease stages for the sociodemographic and clinical data were calculated using one-way ANOVA for normally distributed variables and Kruskal-Wallis tests for K-samples for nonnormally distributed variables. Chi-square tests were performed in order to calculate overall group differences on ATC use between stages I - V.

In order to investigate associations between the independent variables including formal and informal ATC and the dependent variable representing HRQL (EQ-5D VAS score) simple regression analyses were performed. These revealed significant associations for all disease-related variables (TFC, cognitive impairment, disease duration, informant, housing situation), while none of the socio-demographic variables reached significance. Further, we performed multivariate linear regression analyses in order to assess the contribution of the variables of interest and other potentially confounding variables (control variables) on the dependent variable. Based on results of the simple regression analyses and clinical importance, all disease-related variables, except for living situation due to high correlation with TFC of $>0.7$, were entered into multiple regression model as control variables. Additionally, the model was controlled for variables age and education, both known to influence HRQoL $[35,36]$. Variables TFC 
and cognitive impairment were entered as diseasespecific control variables in separate models as they correlated highly with each other and are considered important relating to both variables of interest and HRQoL. Findings are presented in Adjusted $R^{2}$ and in standardized Beta $(\beta)$ values with confidence intervals and partial $r^{2}$. Inspection of violation of assumptions resulted in logarithmical transformation of the values of disease duration. Multicollinearity between independent variables was investigated using inflation factor (VIF). Influential data points were examined using Cook's distance and residual analyses were conducted revealing no outliers among any of the variables included in the analyses. Significance levels were set at $p=0.05$ and all statistical tests were two sided. SPSS version 21.0; SPSS Inc. Chicago IL was used to perform all statistical analyses.

\section{RESULTS}

\section{Description of participants}

Socio-demographic and clinical characteristics of all 84 included patients are presented in Table 1. Disease Stage I included 12 patients (14\%), Stage II 22 patients (26\%), Stage III 19 patients (23\%), Stage IV 14 patients (17\%) and Stage V 17 patients (20\%). The mean age of the patients was 56.7 (SD 11.4) years. Significant overall group differences $(p<0.001)$ were

Table 1

Socio-demographic and clinical characteristics for total sample and divided across disease stages

\begin{tabular}{|c|c|c|c|c|c|c|c|c|}
\hline & & $\begin{array}{c}\text { Complete sample } \\
(\mathrm{N}=84)\end{array}$ & $\begin{array}{l}\text { Stage I } \\
(n=12)\end{array}$ & $\begin{array}{l}\text { Stage II } \\
(n=22)\end{array}$ & $\begin{array}{l}\text { Stage III } \\
(n=19)\end{array}$ & $\begin{array}{l}\text { Stage IV } \\
(n=14)\end{array}$ & $\begin{array}{l}\text { Stage V } \\
(n=17)\end{array}$ & \\
\hline Variables & Categories & $\begin{array}{l}\text { Mean } \\
(\mathrm{SD})\end{array}$ & $\begin{array}{c}\text { Mean } \\
(\mathrm{SD})\end{array}$ & $\begin{array}{l}\text { Mean } \\
(\mathrm{SD})\end{array}$ & $\begin{array}{c}\text { Mean } \\
(\mathrm{SD})\end{array}$ & $\begin{array}{c}\text { Mean } \\
(\mathrm{SD})\end{array}$ & $\begin{array}{l}\text { Mean } \\
\text { (SD) }\end{array}$ & $p$-value \\
\hline \multicolumn{9}{|c|}{ Socio-demographic characteristics } \\
\hline Age $^{*}$ & & $56.7(11.4)$ & $49.8(9.5)$ & $54.6(12.9)$ & $58.9(11.1)$ & $61.1(11.5)$ & $57.8(9.0)$ & 0.084 \\
\hline \multirow[t]{2}{*}{ Education (years)* } & & $12.9(3.5)$ & $14.3(3.3)$ & $13.8(3.8)$ & $11.7(3.2)$ & $12.5(3.7)$ & $12.4(3.3)$ & 0.179 \\
\hline & & $\mathrm{n}(\%)$ & $\mathrm{n}(\%)$ & $\mathrm{n}(\%)$ & $\mathrm{n}(\%)$ & $\mathrm{n}(\%)$ & $\mathrm{n}(\%)$ & $\begin{array}{l}P \text {-value } \\
\text { (2 sided) }\end{array}$ \\
\hline \multirow{2}{*}{ Gender } & $\overline{\text { Female }}$ & $37(44)$ & $5(42)$ & $8(36.4)$ & $7(37)$ & $7(50)$ & $10(59)$ & 0.616 \\
\hline & Male & $47(56)$ & $7(58)$ & $14(63.6)$ & $12(63)$ & $7(50)$ & $7(41)$ & \\
\hline \multirow{2}{*}{ Education } & Lower ( $\leq 12$ years) & $51(60.7)$ & $5(42)$ & $11(50)$ & $15(79)$ & $9(64.3)$ & $11(65)$ & 0.221 \\
\hline & Higher $(>12$ years $)$ & $33(39.3)$ & $7(58)$ & $11(50)$ & $4(21)$ & $5(45.7)$ & $6(35)$ & \\
\hline \multirow[t]{2}{*}{ Marital status } & Single & $36(42.9)$ & $4(33)$ & $7(31.8)$ & $9(47)$ & $8(57.1)$ & $8(47)$ & 0.560 \\
\hline & Married & $48(57.1)$ & $8(67)$ & $15(68.2)$ & $10(53)$ & $6(42.9)$ & $9(53)$ & \\
\hline \multirow[t]{2}{*}{ Occupation $^{\#}$} & Manual & $40(47.6)$ & $5(42)$ & $9(40.1)$ & $12(63)$ & $6(46.1)$ & $8(47)$ & 0.643 \\
\hline & Non-manual & $41(48.8)$ & $7(58)$ & $13(59.1)$ & $7(37)$ & $7(53.8)$ & $7(41)$ & \\
\hline \multirow{2}{*}{ Employment } & Employed & $14(16.7)$ & $11(92)$ & $3(13.6)$ & $0(0)$ & $0(0)$ & $0(0)$ & $<0.001$ \\
\hline & Unemployed & $70(83.3)$ & $1(8)$ & $19(86.4)$ & $19(100)$ & $14(100)$ & $17(100)$ & \\
\hline \multirow[t]{2}{*}{ Housing situation } & Living at home & $52(61.9)$ & $12(100)$ & $22(100)$ & $13(68)$ & $5(35.7)$ & $0(0)$ & $<0.001$ \\
\hline & Not living at home & $32(38.1)$ & $0(0)$ & $0(0)$ & $6(32)$ & $9(64.3)$ & $17(100)$ & \\
\hline \multirow[t]{2}{*}{ Residence } & Rural & $12(14.3)$ & $1(8)$ & $3(13.6)$ & $2(10.5)$ & $3(21.4)$ & $3(18)$ & 0.859 \\
\hline & Urban & $72(85.7)$ & $11(92)$ & $19(86.4)$ & $17(89.5)$ & $11(78.6)$ & $14(82)$ & \\
\hline \multirow[t]{2}{*}{ Informant } & Patient Patient \& & $27(32.1)$ & $9(75)$ & $14(63.6)$ & $4(21)$ & $0(0)$ & $0(0)$ & $<0.001$ \\
\hline & $\begin{array}{l}\text { informant/ } \\
\text { informant only }\end{array}$ & $57(67.9)$ & $3(25)$ & $8(36.4)$ & $15(79)$ & $14(100)$ & $17(100)$ & \\
\hline \multicolumn{2}{|l|}{ Variables } & $\begin{array}{c}\text { Median } \\
\text { (IQR) }\end{array}$ & $\begin{array}{c}\text { Median } \\
\text { (IQR) }\end{array}$ & $\begin{array}{c}\text { Median } \\
(\mathrm{IQR})\end{array}$ & $\begin{array}{c}\text { Median } \\
\text { (IQR) }\end{array}$ & $\begin{array}{c}\text { Median } \\
\text { (IQR) }\end{array}$ & $\begin{array}{c}\text { Median } \\
\text { (IQR) }\end{array}$ & $p$-value \\
\hline \multicolumn{9}{|l|}{ Clinical characteristics } \\
\hline \multicolumn{2}{|l|}{ Disease duration** } & $6(7)$ & $2(2)$ & $5(6)$ & $7(5)$ & $8(7)$ & $11(7)$ & $<0.001$ \\
\hline \multicolumn{2}{|l|}{ Total FAS score** } & $15(17)$ & $24(2)$ & $20(2)$ & $15(4)$ & $5(3)$ & $0(2)$ & $<0.001$ \\
\hline \multirow[t]{2}{*}{ Independence score ${ }^{* * *}$} & & $60(26.5)$ & $95.8(5.1)$ & $79.1(2.9)$ & $64.7(6.3)$ & $40.4(10.8)$ & $20.9(5.7)$ & $<0.001$ \\
\hline & & $\mathrm{n}(\%)$ & $\mathrm{n}(\%)$ & $\mathrm{n}(\%)$ & $\mathrm{n}(\%)$ & $\mathrm{n}(\%)$ & $\mathrm{n}(\%)$ & $\begin{array}{c}P \text {-value } \\
\text { (2-sided) }\end{array}$ \\
\hline \multirow{2}{*}{$\begin{array}{l}\text { Overall cognitive } \\
\text { impairment }\end{array}$} & $\overline{\text { Mild to moderate }}$ & $46(54.8)$ & $12(100)$ & $22(100)$ & $12(63.2)$ & $0(0)$ & $0(0)$ & $<0.001$ \\
\hline & Severe & $34(40,5)$ & $0(0)$ & $0(0)$ & $6(31.6)$ & $12(85.7)$ & $16(94.1)$ & \\
\hline \multirow{2}{*}{ Comorbid conditions } & No(ne) & $48(57.1)$ & $7(58)$ & $9(41)$ & $9(47)$ & $10(71)$ & $13(76)$ & 0.143 \\
\hline & Yes & $36(42.9)$ & $5(42)$ & $13(59)$ & $10(53)$ & $4(29)$ & $4(24)$ & \\
\hline
\end{tabular}

FAS: Functional Assessment Scale; SD: Standard deviation; IQR: Interquartile range; *using ANOVA; ${ }^{* *}$ Kruskall-Wallis for k samples *** normally distributed: reported mean (sd) and Anova; all other variables Chi-square; ${ }^{*} 3$ responses missing ( 1 in Stage IV and 2 in stage $\mathrm{V}) ;{ }^{\#} 4$ patients unable to evaluate (1 in Stage III, 2 in Stage IV, and 1 in Stage IV). 
found for employment, housing situation and informant. Furthermore, overall group differences for disease-specific clinical characteristics were significant $(p<0.001)$. As expected, patients with advanced disease had longer disease duration compared to patients in the early phase of disease, while total scores for scales indicating functional disability (FAS and IS) showed a decline from stage I to stage V. The number of patients with severe cognitive impairment increased in advanced disease (all patients in stage IV and $\mathrm{V}$ had severe cognitive impairment, while all patients in stage I had mild to moderate cognitive impairment). There were no significant group differences for comorbid conditions $(p=0.143)$.

\section{Description of distribution of informal and formal ATC}

Table 2 presents frequencies and percentages of ATC. Overall, approximately one third (36.9\%, $n=31$ ) of all patients had ATC (either formal or informal) with the majority of patients in stages I to III (Stage I: $75 \%, n=9$, Stage II: $63.7 \%, n=14$, Stage III: $36 \%, n=7$, respectively). Formal ATC was most frequent in stage III $(36.8 \%, n=7)$, while informal ATC was most frequent for patients in stages I and II ( $75 \%, n=9$ and $45.5 \%, n=10$, respectively). Overall significant group differences across the five disease stages were found for having and using ATC $(p<0.001)$. Forty four percent of all patients $(n=37)$ had received information about the possibility of receiving ATC. Only $32.1 \%,(n=27)$ had undergone a formal needs assessment for ATC, while even fewer patients $(20.2 \%, n=17)$ had received training for use of the provided ATC. Information regarding ATC provision was predominantly given to patients in stage II $(45.4 \%, n=10)$ and III $(73.7 \%, n=14)$. Information regarding a formal needs assessments and training provided for ATC showed similar patterns. In stage I, four patients $(33.3 \%)$ had received information about ATC and none of the patients in stage I had yet received an evaluation regarding provision of formal ATC or received training. A similar number of patients in the advanced disease phase (stage IV and V) had received information, evaluation and training for the use of ATC. Overall group differences across disease stages were significant for the provision of information about ATC and performance of ATC evaluations ( $p=0.045 \& p=0.006$ respectively), while no general group difference was found for ATC training $(p=0.150)$.

\section{Health-related quality of life}

An average score of 52.1 (SD 26.1) $(n=82)$ was found for overall self-reported HRQoL measured by EQ-5D VAS. Average scores declined across disease stages I to III (stage I: mean $83(\mathrm{SD}=16.4)$; stage II: mean 57.9 ( $\mathrm{SD}=20.3$ ); stage III: mean 49.3 (SD 23.5)) and remained stable in advanced disease (stage IV: mean 35 (25.5); stage V: mean 38.3 (20.9) $(n=15))$.

\section{The relationship between ATC and health-related quality of life}

When investigating the relationship between formal and informal ATC on HRQoL $(n=82)$ using

Table 2

Description of information for ATC

\begin{tabular}{|c|c|c|c|c|c|c|c|c|}
\hline & & $\begin{array}{c}\text { Complete sample } \\
(\mathrm{N}=84)\end{array}$ & $\begin{array}{l}\text { Stage I } \\
(n=12) \\
\end{array}$ & $\begin{array}{l}\text { Stage II } \\
(n=22)\end{array}$ & $\begin{array}{c}\text { Stage III } \\
(n=19)\end{array}$ & $\begin{array}{l}\text { Stage IV } \\
(n=14)\end{array}$ & $\begin{array}{l}\text { Stage V } \\
(n=17)\end{array}$ & \\
\hline Variables & & $\mathrm{n}(\%)$ & $\mathrm{n}(\%)$ & $\mathrm{n}(\%)$ & $\mathrm{n}(\%)$ & $\mathrm{n}(\%)$ & $\mathrm{n}(\%)$ & $P$-value (2-sided) \\
\hline \multirow[t]{3}{*}{ ATC formal/informal } & Formal & $12(14.3)$ & $0(0)$ & $4(18.2)$ & $7(36.8)$ & $1(7.1)$ & $0(0)$ & $P<0.001$ \\
\hline & Informal & $19(22.6)$ & $9(75)$ & $10(45.5)$ & $0(0)$ & $0(0)$ & $0(0)$ & \\
\hline & None & $53(63.1)$ & $3(25)$ & $8(36.4)$ & $12(63.2)$ & $13(92.9)$ & $17(100)$ & \\
\hline \multirow[t]{3}{*}{ ATC use } & Yes & $30(35.7)$ & $9(25)$ & $14(63.6)$ & 7 (36.8) & $0(0)$ & $0(0)$ & $P<0.001$ \\
\hline & No & $48(57.1)$ & $3(75)$ & $8(36.4)$ & $12(63.2)$ & $11(78.6)$ & $14(82.3)$ & \\
\hline & Used previously & $6(7.1)$ & $0(0)$ & $0(0)$ & $0(0)$ & $3(21.4)$ & $3(17.7)$ & \\
\hline \multirow[t]{2}{*}{ ATC information* } & Yes & $37(44)$ & $4(33.3)$ & $10(45.4)$ & $14(73.7)$ & $4(28.6)$ & $5(29.4)$ & $P=0.045$ \\
\hline & No & $46(54.8)$ & $8(66.7)$ & $12(54.5)$ & $5(26.3)$ & $10(71.4)$ & $11(64.7)$ & \\
\hline \multirow[t]{2}{*}{ ATC evaluation** } & Yes & $27(32.1)$ & $0(0)$ & $7(31.8)$ & $12(63.2)$ & $4(28.6)$ & $4(23.5)$ & $P=0.006$ \\
\hline & No & $56(66.7)$ & $12(100)$ & $15(68.2)$ & $7(36.8)$ & $9(64.3)$ & $13(76.4)$ & \\
\hline \multirow[t]{2}{*}{ ATC training } & Yes & $17(20.2)$ & $0(0)$ & $5(22.7)$ & $7(36.8)$ & $2(14.3)$ & $3(17.6)$ & $P=0.150$ \\
\hline & No & $67(79.8)$ & $12(100)$ & $17(77.3)$ & $12(63.2)$ & $12(85.7)$ & $14(82.4)$ & \\
\hline
\end{tabular}

ATC: Assistive Technologies for Cognition/cognitive disabilities. Chi-squares were used to calculate overall group differences; ${ }^{*} 1$ missing in Stage V; ${ }^{* *} 1$ missing in Stage IV. 
simple regression analysis, we found a positive $\beta$ value that reached significance for informal ATC, indicating that informal ATC was associated with higher HRQoL ( $\beta$ value $=0.356, \beta$ 95\% CI: $8.45-$ $34.16, p=0.001)$. The formal ATC was not significantly associated with HRQoL ( $\beta$ value $=-0.045$, $\beta$ 95\% CI $-19.04-12.58, p=0.685)$ in the simple regression analysis.

Results of the multivariate linear regression analysis investigating the associations between having formal and informal ATC and HRQoL $(n=82)$, are displayed in Table 3 . The final model controlled for TFC score, disease duration, informant, age and education explained one-third of the variance in HRQL scores (adjusted $\mathrm{R}^{2}=30 \%, p<0.001$ ). The model produced only one significant predictor, the TFC. TFC had a negative Beta value $(\beta$ value $=-0.564, \beta 95 \% \mathrm{CI}$ $\left.1.47-5.34, \mathrm{r}^{2}=0.142, p=0.001\right)$ showing that a higher TFC score corresponded to higher HRQoL, and explained almost all variance in the model. Formal ATC, informal ATC or other control variables were not associated with HRQoL in the final model.

Collinearity statistics were found to be acceptable (VIF: $1.15-2.99$ ). No outliers were identified. No single case had undue influence on the model as indicated by Cook's distance $(\mathrm{D}=\max 0.145)$. The external validation of the model performed using the variable cognitive impairment instead of TFC showed the same value of the explained variance and other results.

\section{DISCUSSION}

The current study is the first to describe ATC and its association with HRQoL in HD. We found that 31 of 84 patients had ATC. Use of ATC was most frequent in disease stages I-III, in patients with mild to moderate cognitive impairment, with informal ATC most frequently used in disease stages I-II and formal ATC in disease stages II-III. Information about ATC, needs evaluation and training was provided most frequently in stages II-III. Multiple regression analysis showed that neither formal nor informal ATC were significantly associated with HRQoL. Of the assessed variables, functional capacity as assessed by TFC was the only variable significantly associated with HRQoL.

We found that relatively few patients in this study used formal ATC. The fact that a minority of the patients had formal ATC may be explained by differences between formal and informal ATC: informal ATC is introduced by the patients themselves in order to compensate for self-experienced reduced cognitive function and maintain their daily functioning. These items are well-known to the patients and easily accessible. Formal ATC, on the other hand, requires an implementation process and training. Additionally, patients in earlier disease stages have less pronounced cognitive impairment and higher functional capacity. They may be able to recognize and compensate for early symptoms of cognitive impairment by using such familiar objects. Needs for more complex aids may arise as the disease progresses and cognitive impairments increase in severity. More than 50\% of the assessed patients had not received information or undergone a needs assessment for ATC, and few had received training. This finding is in line with other studies on patients with cognitive disabilities, showing that patients often do not receive information concerning ATC, and pointing to lack of knowledge regarding available ATC and a lack of trained personnel to implement them $[37,38]$. In this study formal ATC was most frequently used in disease stages II-III, while informal ATC was used in stages I and II. This could be a result of the needs for formal ATC arising later in the course of disease. An additional explanation could be lack of awareness for and knowledge about the provision of formal ATC among professionals working with HD patients resulting in late performance of ATC

Table 3

Results of linear regression analyses on HRQoL $(\mathrm{N}=82)$

\begin{tabular}{lrccc}
\hline Independent Variables & \multicolumn{1}{c}{$\beta$} & $\beta(95 \%$ CI $)$ & Partial $r^{2}$ & $p$-value \\
\hline Formal ATC & -0.067 & $-19.05-9.5$ & 0.006 & 0.511 \\
Informal ATC & 0.018 & $-14.8-17.03$ & 0.002 & 0.889 \\
TFC & 0.564 & $1.47-5.34$ & 0.142 & 0.001 \\
Disease duration & -0.156 & $-11.63-2.56$ & 0.021 & 0.207 \\
Informant & 0.097 & $-8.81-19.51$ & 0.008 & 0.454 \\
Age & -0.108 & $-2.29-0.67$ & 0.016 & 0.280 \\
Education & 0.037 & $-0.37-0.54$ & 0.002 & 0.715 \\
\hline
\end{tabular}

Note: $\beta=$ standardized coefficients, partial $r^{2}=$ squared partial correlation coefficients. $R$-square $=0.36$, Adjusted $R^{2}=0.30, p<0.001$. 
needs assessment and implementation. The latter may negatively influence patients' ability to benefit from ATC as the progressive nature of cognitive impairment may reduce ability to learn to use ATC through training and thereby reduce the period of time for effectively being able to use ATC. Overall use of ATC was least frequent in stages IV-V, including the patients with more severe cognitive impairment. This may be expected as patients in advanced disease stages have global cognitive impairment (dementia) and motor symptoms causing increasing difficulty applying external aids.

In this study, we did not find an association between ATC and HRQoL. The TFC was the only factor significantly associated with HRQoL. This finding is in line with previous studies [12, 39, 40]. One possible explanation may be that improving HRQoL through the use of ATC requires more than access to devices. One may have to take into account the interactions between the device and everyday life environments in order to make ATC an effective intervention [41]. Prior studies have identified critical factors for successful use of ATC underlining the importance of establishing a match between the person with impaired cognition and the ATC through comprehensive assessment of individual characteristics $[20,26,37]$. These characteristics include personal characteristics of the individual, the environment and the ATC [37, 41]. Our results may indicate that ATC has not been successfully implemented. Several reviews and clinical studies show promising results for ATC as a mean to support and maintain cognitive function and to improve functional ability in patients with impaired cognition [22, 23, 42-46]. An improvement in the quality of life (QoL) and in the ability to perform daily activities was also found in a recently published study on home-based electronic assistive technology for memory in individuals with memory deficits [43]. ATC is thought to positively affect HRQoL through improving functional ability. Therefore, it may be that the effect of ATC is reflected in the TFC score in the present study.

\section{Limitations and strengths}

A number of limitations of the present study should be addressed. Firstly, this is a cross-sectional study that prevents us from describing the process of ATC implementation over time and discussing causal relationships. Secondly, our evaluation of cognitive impairment was based on clinical evaluation during the interview with the patient without using a standardized instrument. However, we pre-defined three categories of cognitive impairment (mild, moderate and severe) based on our clinical knowledge of cognitive functioning and work experience with patients suffering HD. The high correlation $(>0.9)$ between cognitive impairment and TFC indicates that our evaluation can be considered sufficiently reliable. Thirdly, the present study does not include other disease-specific clinical assessments, which may provide more information about the characteristics of the patients who use ATC, and may help to tease apart associations between ATC and HRQoL. It should further be noted that a disease specific measure of HRQoL could potentially have been more sensitive to an association between ATC and HRQoL. Yet we consciously chose a generic measure in the form of the EQ-5D VAS as it is less complicated and therefore, easier to administer for advanced patients, which we specifically aimed to recruit. Some form of population bias cannot be excluded as patients with reduced self-awareness may not be in contact with healthcare institutions. They may also be more likely to decline participating in the study as they perceive themselves symptom free. Yet, despite reducing the statistical power, the response rate of 53.2\% included in the analyses of this study can be considered satisfactory, given the clinical picture of HD. The present study also comes with strengths. Patients in stages IV and V (advanced stages) are relatively equally represented. Moreover, this is the only study to describe use of ATC in HD, a potential additional resource to existing comprehensive healthcare services.

\section{Clinical recommendations and recommendations for future research}

Previous studies on ATC and cognitive impairment propose that ATC can be effective and that a comprehensive process of identifying needs, personal and environmental factors, implementation through training (matching the person with the device) increases the likeliness of patients being able to benefit from ATC. The results of the present study suggest the need for increased awareness about ATC as an intervention to support and compensate cognitive abilities in HD in Norway. Our findings further suggest that professionals need to be aware of the requirements for successful implementation and awareness of the process towards successfully providing ATC to patients with HD. It is important to bear in mind the complex and changing character of HD, including motor impairments, calling for regular monitoring of ATC 
needs and use. The relatively low number of patients using formal ATC and the absence of an association between ATC and HRQoL may indicate an insufficient ATC implementation process, lacking comprehensive and individually tailored assessment. The results call for further research on ATC as a treatment intervention, and for further investigation of the effectiveness of ATC on cognition and ADL in HD. Future studies should also seek to further tease apart associations between ATC and other disease specific factors, including cognitive function and functional abilities, and HRQoL.

\section{Conclusion}

ATC was used mainly in stages I-III, in patients with mild to moderate cognitive impairment. Use of informal ATC was most frequent in stages I II, and formal ATC in stages II-III. Information about ATC, needs evaluation and training was predominantly provided to patients in stages II-III. No association between ATC and HRQoL was found. Results may reflect lack of awareness and knowledge about the availability of ATC among healthcare professionals. Results further suggest the importance of a thorough assessment and implementation process matching device with the individual, requiring healthcare professionals to see the patient and ATC in a social context.

\section{CONFLICTS OF INTEREST}

The authors have no conflicts of interest to report.

\section{ACKNOWLEDGMENTS}

The present study was funded by the Norwegian Research Council (209748). We thank the patients, their family members and their healthcare professionals for their time and effort as part of participating in the study. Additionally, we thank Kristin Iversen, Gunvor Ruud, Nancy Borgerød and Ragnhild Wehus, for their assistance with the recruitment of participants.

\section{REFERENCES}

[1] Paulsen JS, Langbehn DR, Stout JC, Aylward E, Ross CA, Nance M, et al. Detection of Huntington's disease decades before diagnosis: The Predict-HD study. J Neurol Neurosurg Psychiatry. 2008;79(8):874-80.
[2] Stout JC, Paulsen JS, Queller S, Solomon AC, Whitlock $\mathrm{KB}$, Campbell JC, et al. Neurocognitive signs in prodromal Huntington disease. Neuropsychology. 2011;25(1): $1-14$.

[3] Tabrizi SJ, Scahill RI, Owen G, Durr A, Leavitt BR, Roos RA, et al. Predictors of phenotypic progression and disease onset in premanifest and early-stage Huntington's disease in the TRACK-HD study: Analysis of 36-month observational data. Lancet Neurol. 2013;12(7):637-49.

[4] Papoutsi M, Labuschagne I, Tabrizi SJ, Stout JC. The cognitive burden in Huntington's disease: Pathology, phenotype, and mechanisms of compensation. Mov Disord. 2014;29(5):673-83.

[5] Stout JC, Glikmann-Johnston Y, Andrews SC. Cognitive assessment strategies in Huntington's disease research. J Neurosci Methods. 2016;265:19-24.

[6] Georgiou-Karistianis N, Scahill R, Tabrizi SJ, Squitieri F, Aylward E. Structural MRI in Huntington's disease and recommendations for its potential use in clinical trials. Neurosci Biobehav Rev. 2013;37(3):480-90.

[7] Rosas HD, Feigin AS, Hersch SM. Using advances in neuroimaging to detect, understand, and monitor disease progression in Huntington's disease. NeuroRx. 2004;1(2): 263-72.

[8] Dumas EM, van den Bogaard SJ, Middelkoop HA, Roos RA. A review of cognition in Huntington's disease. Frontiers in bioscience (Scholar edition). 2013;5:1-18.

[9] Bates G, Tabrizi S, Jones L. Huntingtons disease: Oxford University Press; 2014.

[10] Nehl C, Paulsen JS. Cognitive and psychiatric aspects of Huntington disease contribute to functional capacity. J Nerv Ment Dis. 2004;192(1):72-4.

[11] Mitchell AJ, Kemp S, Benito-León J, Reuber M. The influence of cognitive impairment on health-related quality of life in neurological disease. Acta Neuropsychiatr. 2010;22(1):2-13.

[12] Read J, Jones R, Owen G, Leavitt BR, Coleman A, Roos RA, et al. Quality of life in Huntington's disease: A comparative study investigating the impact for those with pre-manifest and early manifest disease, and their partners. J Huntingtons Dis. 2013;2(2):159-75.

[13] Ross CA, Pantelyat A, Kogan J, Brandt J. Determinants of functional disability in Huntington's disease: Role of cognitive and motor dysfunction. Mov Disord. 2014;29 (11):1351-8.

[14] Banaszkiewicz K, Sitek EJ, Rudzinska M, Soltan W, Slawek J, Szczudlik A. Huntington's disease from the patient, caregiver and physician's perspectives: Three sides of the same coin? J Neural Transm (Vienna). 2012;119(11):1361-5.

[15] Paulsen JS. Cognitive impairment in Huntington disease: Diagnosis and treatment. Curr Neurol Neurosci Rep. 2011;11(5):474-83.

[16] Nance MA. Comprehensive care in Huntington's disease: A physician's perspective. Brain Res Bull. 2007;72(2-3): 175-8.

[17] Veenhuizen RB, Kootstra B, Vink W, Posthumus J, van Bekkum P, Zijlstra M, et al. Coordinated multidisciplinary care for ambulatory Huntington's disease patients. Evaluation of 18 months of implementation. Orphanet J Rare Dis. 2011;6:77.

[18] Veenhuizen RB, Tibben A. Coordinated multidisciplinary care for Huntington's disease. An outpatient department. Brain Res Bull. 2009;80(4-5):192-5.

[19] Andrews SC, Dominguez JF, Mercieca EC, GeorgiouKaristianis N, Stout JC. Cognitive interventions to enhance 
neural compensation in Huntington's disease. Neurodegener Dis Manag. 2015;5(2):155-64.

[20] Frank Lopresti E, Mihailidis A, Kirsch N. Assistive technology for cognitive rehabilitation: State of the art. Neuropsychol Rehabil. 2004;14(1-2):5-39.

[21] Gillespie A, Best C, O'Neill B. Cognitive function and assistive technology for cognition: A systematic review. J Int Neuropsychol Soc. 2012;18(1):1-19.

[22] de Joode E, van Heugten C, Verhey F, van Boxtel M. Efficacy and usability of assistive technology for patients with cognitive deficits: A systematic review. Clin Rehabil. 2010;24(8):701-14.

[23] Wilson B, Emslie H, Quirk K, Evans J. Reducing everyday memory and planning problems by means of a paging system: A randomised control crossover study. J Neurol Neurosurg Psychiatry. 2001;70(4):477-82.

[24] Cole E, Dehdashti P, Petti L, Angert M. Design and outcomes of computer-based cognitive prosthetics for brain injury: A field study of three subjects. NeuroRehabilitation. 1994;4(3):174-86.

[25] Oriani M, Moniz-Cook E, Binetti G, Zanieri G, Frisoni GB, Geroldi C, et al. An electronic memory aid to support prospective memory in patients in the early stages of Alzheimer's disease: A pilot study. Aging Ment Health. 2003;7(1):22-7.

[26] Scherer MJ, Hart T, Kirsch N, Schulthesis M. Assistive technologies for cognitive disabilities. Crit Rev Phys Rehabil Med. 2005;17(3).

[27] Scherer MJ. Living in the state of stuck: How assistive technology impacts the lives of people with disabilities: Brookline Books; 2005.

[28] Ferm U, Sahlin A, Sundin L, Hartelius L. Using Talking Mats to support communication in persons with Huntington's disease. Int J Lang Commun Disord. 2010;45(5): 523-36.

[29] Hallberg L, Mellgren E, Hartelius L, Ferm U. Talking Mats in a discussion group for people with Huntington's disease. Disabil Rehabil Assist Technol. 2013;8(1):67-76.

[30] EuroQol-a new facility for the measurement of healthrelated quality of life. Health Policy. 1990;16(3):199-208.

[31] Nord E. EuroQol: Health-related quality of life measurement. Valuations of health states by the general public in Norway. Health Policy. 1991;18(1):25-36.

[32] Hocaoglu MB, Gaffan EA, Ho AK. The Huntington's Disease health-related Quality of Life questionnaire (HDQoL): A disease-specific measure of health-related quality of life. Clin Genet. 2012;81(2):117-22.

[33] Carlozzi NE, Victorson D, Sung V, Beaumont JL, Cheng $\mathrm{W}$, Gorin B, et al. HD-PRO-TRIAD validation: A patientreported instrument for the symptom triad of Huntington's disease. Tremor Other Hyperkinet Mov (N Y). 2014; 4:223.
[34] Carlozzi NE, Kratz AL, Downing NR, Goodnight S, Miner JA, Migliore N, et al. Validity of the 12-item World Health Organization Disability Assessment Schedule 2.0 (WHODAS 2.0) in individuals with Huntington disease (HD). Qual Life Res. 2015;24(8):1963-71.

[35] Ferrans CE, Zerwic JJ, Wilbur JE, Larson JL. Conceptual model of health-related quality of life. J Nurs Scholarsh. 2005;37(4):336-42.

[36] Mielck A, Reitmeir P, Vogelmann M, Leidl R. Impact of educational level on health-related quality of life (HRQL): Results from Germany based on the EuroQol 5D (EQ-5D). Eur J Public Health. 2013;23(1):45-9.

[37] Scherer MJ. Assessing the benefits of using assistive technologies and other supports for thinking, remembering and learning. Disabil Rehabil. 2005;27(13):731-9.

[38] Adolfsson P, Lindstedt H, Pettersson I, Hermansson LN, Janeslatt G. Perception of the influence of environmental factors in the use of electronic planning devices in adults with cognitive disabilities. Disabil Rehabil Assist Technol. 2014:1-8.

[39] Ho AK, Gilbert AS, Mason SL, Goodman AO, Barker RA. Health-related quality of life in Huntington's disease: Which factors matter most? Mov Disord. 2009;24(4):574-8.

[40] Brugger F, Hepperger C, Hametner EM, Holl AK, Painold A, Schusterschitz C, et al. Predictors of mental and physical quality of life in Huntington's disease. Nervenarzt. 2015;86(2):167-73.

[41] Scherer MJ, Federici S. Why people use and don't use technologies: Introduction to the special issue on assistive technologies for cognition/cognitive support technologies. NeuroRehabilitation. 2015;37(3):315-9.

[42] Mihailidis A, Boger JN, Craig T, Hoey J. The COACH prompting system to assist older adults with dementia through handwashing: An efficacy study. BMC Geriatr. 2008;8:28.

[43] Boman IL, Bartfai A, Borell L, Tham K, Hemmingsson H. Support in everyday activities with a home-based electronic memory aid for persons with memory impairments. Disabil Rehabil Assist Technol. 2010;5(5):339-50.

[44] Jamieson M, Cullen B, McGee-Lennon M, Brewster S, Evans JJ. The efficacy of cognitive prosthetic technology for people with memory impairments: A systematic review and meta-analysis. Neuropsychol Rehabil. 2014;24(3-4): 419-44.

[45] Adolfsson P, Lindstedt H, Janeslatt G. How people with cognitive disabilities experience electronic planning devices. NeuroRehabilitation. 2015;37(3):379-92.

[46] Leopold A, Lourie A, Petras H, Elias E. The use of assistive technology for cognition to support the performance of daily activities for individuals with cognitive disabilities due to traumatic brain injury: The current state of the research. NeuroRehabilitation. 2015;37(3):359-78. 